\title{
Feeder Type Affects Growth in Weanling Horses
}

\author{
Carol Jean Thompson and Kevin Halden Kline \\ Department of Animal Sciences, University of Illinois, Urbana, IL 61801, USA
}

\begin{abstract}
In the interest of decreasing feed costs while maximizing the growth of weanling horses, this study examined the potential difference in the average daily gain (ADG), gain to feed ratio (G/F), and apparent dry matter and crude protein digestibility in horses fed with the same diet provided in different feeder types. Sixteen weanling standardbred horses were used for the duration of the 9-week study. The horses were given $2.5 \%$ of their body weight in hay and grain daily, $2 \%$ hay and $0.5 \%$ grain, as fed in two equal feedings at 7:00 am and 7:00 pm. The first treatment used a combined hay and grain feeder with the hay rack positioned over a manger compartment. The second treatment provided hay in an open hay rack and grain in a separate, open-topped feed tub, not positioned under the hay rack. The two groups, with eight horses-four female and four male in each group, were fed in one manner or the other for the length of the study. The weanlings fed in the combined hay and grain feeder had a greater ADG (0.52 kg/d vs. $0.41 \mathrm{~kg} / \mathrm{d})$ and G/F (0.06 vs. 0.05) than the horses with the separate hay and grain feeders. Both ADG and G/F means between treatments were statistically different $(P<0.05)$. There was not a significant difference $(P>0.05)$ in the apparent digestibility of dry matter or crude protein between the two groups. Therefore, it was concluded that the combined feeding system resulted in greater growth and apparent G/F most likely due to decreased feed wastage; however, apparent digestibility was not different between feeding systems.
\end{abstract}

Key words: Horse, growth, digestibility, feeder.

\section{Introduction}

With the continued rise in the price of hay suitable for horses, coupled with high grain costs, horse owners always look for ways to reduce feed costs. An important way to decrease expense is to decrease feed wastage. A past study by Andrews et al. [1] examined the growth and plasma glucose on weanlings fed alfalfa cubes and grain either in a single container or two separate feeders. However, fewer horse owners feed alfalfa cubes as the forage source for their horses, and the most common forage is baled hay. A similar study done by Flores et al. [2] looked at the effect on growth and gastric ulceration in weanlings fed hay cubes and grain separately versus together, but that study focused on the processing method of the feed, not the effect of the feed being fed in different types of feeders. Another study by Bonoma et al. [3] looked at the possibility of replacing a portion of a complete pelleted feed mixture with

Corresponding author: Kevin Halden Kline, Ph.D., professor, research field: equine feeding management. distiller's dried grains with solubles and examined the effect on growth, but did not evaluate the most efficient way to provide the feed. Martinson et al. [4] looked at the effects of round bale feeder type on hay waste and change in body weight. It found significant differences in the body weight of the horses depending on whether or not a feeder was used to present the round bale. Similarly, Buskirk el al. [5] found that round bale feeder design affects the utilization of the hay in beef cattle. Several other studies [6-9] have documented the importance of proper storage and protection of large round bales to reduce nutrient losses. However, specific information regarding efficient utilization of the more commonly fed hay package for horses, small square bales, along with grain, is lacking. Martinson et al. [4] found that all of the feeders used had decreased wastage of hay compared to no feeder at all. However, in that study the horses were fed only hay, not combination of hay and grain. Therefore, there is a need to do a study to examine how both hay and grain were presented to weanling horses and whether it could provide more 
useful information. The objective was to determine which of two feeding systems would be the most desirable for delivering feed to the horses measured by differences in ADG and G/F. The hypotheses were that horses consuming both hay and grain from a combined hay and grain feeder, which held the hay above a manger positioned below the hay feeder compartment, would have the greater average daily gain (ADG), gain to feed ratio $(\mathrm{G} / \mathrm{F})$ and apparent digestibility as compared to feeding the hay and grain in separate hay racks and open feed tubs.

\section{Materials and Methods}

This study examined two common feeding systems using three feeder types shown in Fig. 1. It evaluated weanling growth and apparent digestibility differences in horses consuming baled hay and grain in separate hay racks and open tubs or in a combined hay and grain feeder. Sixteen weanling standardbred horses-eight colts and eight fillies, were used to evaluate the effects of feeder type on growth and apparent digestibility. The horses were randomly assigned within sex to insure four colts and four fillies in each treatment group. The horses were selected from the University of Illinois (Urbana-Champaign, IL) herd, in which all were foaled and raised in the same facilities. The horses were in good health at the beginning and throughout the study. At the start of the study, the fillies had an average weight of $293 \mathrm{~kg}$ with a standard deviation of $20 \mathrm{~kg}$, and the colts had an average weight of $303 \mathrm{~kg}$ with a standard deviation of $33 \mathrm{~kg}$. The horses were kept in individual pens with exercise areas of approximately $70 \mathrm{~m}^{2}$ per horse and provided run-in sheds of approximately $13 \mathrm{~m}^{2}$ for shelter. The sheds were bedded with wood shavings, the remaining area of the runs was covered with soil and neither area had any grass or weeds.

The horses were fed no additional hay or grain beyond the prescribed diet. Horses were weighed on an electronic platform scale at the beginning and end of the study, and weekly during the study. The weanlings were fed $2.0 \%$ of their body weight in hay and $0.5 \%$ grain (adjusted weekly for body weight) split between two feedings, once at 7:00 am and again at 7:00 pm. Horses were fed the hay and grain in either a single combined hay and grain feeder (treatment C) or in a separate hay rack for the hay and feed tub for the grain (treatment S). Hay and grain were weighed on a digital electric platform scale before each feeding. Hay flakes were placed into the combined feeders and hay racks through the topmost opening, while grain was placed into the bottom manger of the combined feeder and into the open-top feed tubs. The design of the feeders is shown in Fig. 1.

All feeders were mounted $100 \mathrm{~cm}$ above the floor. At a preliminary one week feeding period before the start of study, it was found that all horses consumed $2.0 \%$ of their body weight daily of the hay used in the

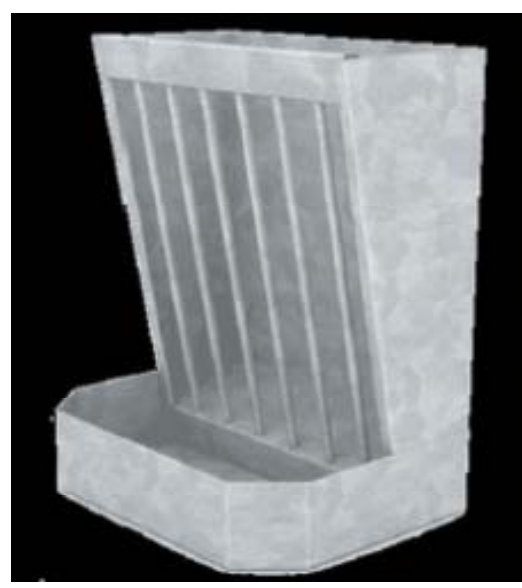

(a) Combined hay/grain feeder

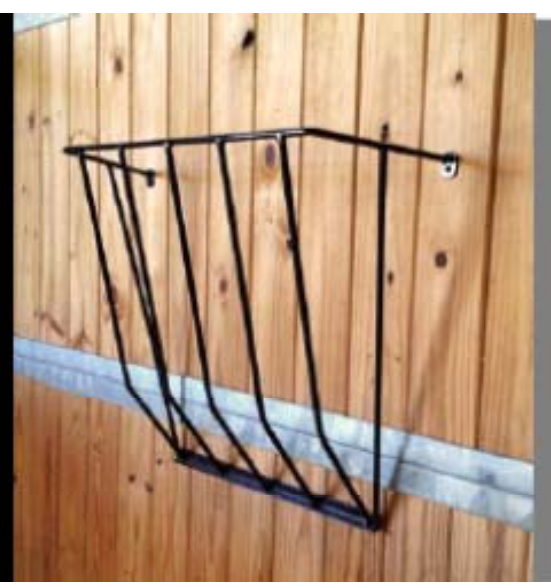

(b) Separate hay rack

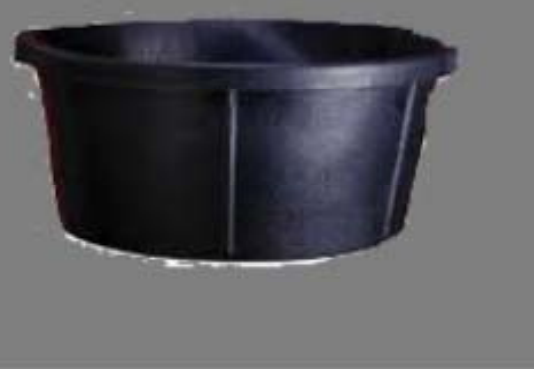

(c) Separate feed tub

Fig. 1 Feeder types used to feed the weanling horses. 
study and $0.5 \%$ of grain without any measurable dietary remnants in the feeders. Therefore, the feeding rate was less than the ad libitum consumption rate. However, no attempt was made to quantify any wasted hay and grain that may have disappeared into the floor and bedding material, as this study was designed to represent practical feeding protocols used by horse owners. Samples of the hay and grain were collected weekly, beginning at the start of the study. The hay was an alfalfa/grass mix and the grain was a sweet feed mix purchased from a local feed store. Hay bale core samples were collected using a stainless steel hay probe and power drill.

Then, freshly voided fecal samples were collected in the morning and evening for the final three days of the study. The fecal samples were dried and sent along with the feed samples to Equi-analytical Laboratories in Ithaca, NY to be analyzed for moisture (\%), crude protein (\%) and acid insoluble ash (\%). Acid insoluble ash (AIA) was used as an internal indigestible marker to calculate apparent digestibility of dry matter and crude protein. Apparent nutrient digestibility (AND) was calculated using Eq. (1):

AND $=100 \times\{1-[($ AIA in feed $(\%) / A I A$ in feces $(\%)] \times[$ nutrient in feces (\%)/nutrient in feed (\%)] $\}$ (1)

The G/F for each horse was determined by Eq. (2): $\mathrm{G} / \mathrm{F}=$ (the total kilograms of body weight gain) /(total kilograms of feed provided)

The term G/F is used in the current study, so as not to infer differences in true feed efficiency, which would include consideration of wasted feed, rather than simply the feed provided. ADG was determined as Eq. (3):

$$
\mathrm{ADG}=\frac{\text { the total kilograms of body weight gain }}{\text { the total number of days on feed }}
$$

Differences between treatments were statistically analyzed using $t$-tests. This study was approved and performed under the guidelines adopted by the University of Illinois Institutional Animal Care and Use Committee.

\section{Results}

Analysis of the hay and grain for the mean concentration of moisture, and dry matter concentrations of crude protein and acid insoluble ash fed daily is shown in Table 1 . The horses on treatment $\mathrm{C}$ had a greater ADG $(P<0.05)$ than the horses on treatment $\mathrm{S}$ (Table 2). The horses on treatment $\mathrm{C}$ also had a higher gain to $\mathrm{G} / \mathrm{F}(P<0.05)$ than horses on treatment $S$ (Table 3). There was not a significant difference in the apparent digestibility of dry matter or crude protein between the two treatments $(P>0.05)$. The mean apparent digestibility of dry matter for horses on treatment $\mathrm{C}$ was $70.3 \%$ and was $67.0 \%$ for

Table 1 Chemical analysis of hay and grain.

\begin{tabular}{llll}
\hline Feed & Moisture (\%) & $\begin{array}{l}\text { Crude protein (\%) } \\
\text { DM basis }\end{array}$ & $\begin{array}{l}\text { Acid insoluble ash (\%) } \\
\text { DM basis }\end{array}$ \\
\hline Hay & 7.60 & 18.90 & 1.10 \\
Grain & 10.50 & 14.70 & 0.50 \\
Mean in daily diets & 8.18 & 18.06 & 0.98 \\
\hline
\end{tabular}

DM: dry matter.

Table 2 Average daily gain.

\begin{tabular}{|c|c|c|c|c|c|c|c|c|}
\hline \multirow{2}{*}{ Treatment } & \multirow{2}{*}{$\mathrm{N}$} & \multicolumn{3}{|c|}{ Average daily gain } & \multirow{2}{*}{-SD } & \multirow[b]{2}{*}{$\mathrm{SE}$} & \multirow[b]{2}{*}{$t$ value } & \multirow{2}{*}{$\operatorname{Pr}>|t|$} \\
\hline & & Mean & Minimum & Maximum & & & & \\
\hline $\mathrm{C}$ & 8 & 0.5219 & 0.3490 & 0.6030 & 0.1048 & 0.0371 & & \\
\hline $\mathrm{S}$ & 8 & 0.4106 & 0.2540 & 0.5080 & 0.0820 & 0.0290 & & \\
\hline Diff (C-S) & & 0.1112 & & & 0.0941 & 0.0470 & 2.36 & 0.0330 \\
\hline
\end{tabular}

Horses in treatment $\mathrm{C}$ were fed the hay and grain in a single combined hay and grain feeder, in treatment $\mathrm{S}$ were in a separate hay rack for the hay and feed tub for the grain.

SD: standard deviation, SE: standard error, Diff (C-S): difference between means of treatments C and S. 
Table 3 Ratio of gain and feed.

\begin{tabular}{|c|c|c|c|c|c|c|c|c|}
\hline \multirow{2}{*}{ Treatment } & \multirow{2}{*}{$\mathrm{N}$} & \multicolumn{3}{|c|}{ Ration of gain and feed } & \multirow{2}{*}{$-S D$} & \multirow{2}{*}{ SE } & \multirow{2}{*}{$t$ value } & \multirow{2}{*}{$\operatorname{Pr}>|t|$} \\
\hline & & Mean & Minimum & Maximum & & & & \\
\hline $\bar{C}$ & 8 & 0.0688 & 0.0470 & 0.0850 & 0.0142 & 0.00501 & & \\
\hline S & 8 & 0.0533 & 0.0330 & 0.0660 & 0.0106 & 0.00376 & & \\
\hline Diff (C-S) & & 0.0155 & & & 0.0125 & 0.00627 & 2.47 & 0.0268 \\
\hline
\end{tabular}

Table 4 Apparent digestibility of dry matter.

\begin{tabular}{lllllllll}
\hline \multirow{2}{*}{ Treatment } & \multirow{2}{*}{$\mathrm{N}$} & \multicolumn{2}{c}{ Apparent digestibility of dry matter } & \multirow{2}{*}{ SD } & \multirow{2}{*}{ SE } & \multirow{2}{*}{$\operatorname{Pr}>|t|$} \\
\cline { 2 - 6 } & & Mean & Minimum & Maximum & & & \\
\hline C & 8 & 70.2600 & 59.1700 & 76.1000 & 5.2635 & 1.8609 & & \\
S & 8 & 67.0075 & 51.0000 & 80.0000 & 9.6630 & 3.4164 & & 0.4172 \\
\hline Diff (C-S) & & 3.2525 & & & 7.7807 & 3.8903 & 0.84 & \\
\hline
\end{tabular}

Table 5 Apparent digestibility of crude protein.

\begin{tabular}{|c|c|c|c|c|c|c|c|c|}
\hline \multirow{2}{*}{ Treatment } & \multirow{2}{*}{$\mathrm{N}$} & \multicolumn{3}{|c|}{ Apparent digestibility of crude protein } & \multirow{2}{*}{$-\mathrm{SD}$} & \multirow{2}{*}{$\mathrm{SE}$} & \multirow{2}{*}{$t$ value } & \multirow{2}{*}{$\operatorname{Pr}>|t|$} \\
\hline & & Mean & Minimum & Maximum & & & & \\
\hline $\mathrm{C}$ & 8 & 75.9613 & 64.1300 & 80.9800 & 5.3048 & 1.8755 & & \\
\hline$\underline{\mathrm{S}}$ & 8 & 75.9900 & 66.7000 & 84.5300 & 6.1849 & 2.1867 & & \\
\hline Diff (C-S) & & -0.0287 & & & 5.7617 & 2.8808 & -0.01 & 0.9922 \\
\hline
\end{tabular}

horses on treatment S (Table 4). No difference $(P>$ 0.05 ) was found in apparent crude protein digestibility between treatments, as horses on both treatments had approximately $76 \%$ apparent digestibility of crude protein (Table 5).

\section{Discussion}

This study found that the type of feeder used to provide hay and grain to weanling horses is important for maximizing $\mathrm{ADG}$ and $\mathrm{G} / \mathrm{F}$. Determining the most effective feeder type for the maximum feed utilization allows horse owners to spend less money on feed, and ensures the horses are receiving more of the amount of food offered by the caretaker. This type of information is helpful for growing horses, as in this study, but would also be useful for other categories of horses with high nutrient demands, such as gestating or lactating mares and high-performance horses. Efficient feed use is important to horse owners and decreases production costs. Martinson et al. [4] compared the costs and economics of the length of time required for various feeders to pay for themselves in savings related to less wasted hay. In all cases, feeders that more effectively reduced hay waste paid for themselves over time.
The current study found that feeding hay and grain in combination of hay and grain feeders with narrowly-spaced bars and enclosed sides in the hay section of the feeder, with a manger directly beneath the hay section, allowed for better ADG and G/F in weanlings. It is likely that these differences are due to differences in hay and grain wastage, although the amount of feed waste was not able to be measured; rather, equal rates of hay and grain were provided to horses on each feeding system and the performance of the horses was the measured to be effected. It is likely that hay wastage was more important in the current study than grain wastage, simply because the hay contained the majority of the nutrients, while only $20 \%$ of the diet was grain. However, based on simply observing the feeding behavior of the horses, more grain appeared to be tossed to the floor from the open-topped feed tubs than from the combination of hay and grain feeder, so the results are likely due to a combination of both hay and grain loss. Additionally, the combination feeder clearly had more of the leaves from the hay being retained in the manger beneath the hay section of the feeder, while many leaves from hay fed in the plain hay racks were observed to fall to the 
floor while horses fed. However, a definitive answer to the question of the relative contribution of hay versus grain wastage to the performance of horses in this study is beyond the scope of this study. Horses were observed to routinely attempt to pick up feed that was scattered beneath the feeders, but the success rates of the horses recovering dropped feed was not measured. What can be stated is that providing hay and grain in more typically-used open hay racks and tub feeders resulted in reduced growth in the animals in this study as compared to the animals fed using a combination of hay and grain feeder. These results are consistent with the findings of Martinson et al. [4] and Buskirk et al. [5] in their studies of horses and cattle, in which using different hay feeders resulted in different degrees of feed wastage. This study only compared two different feeding systems using three types of feeders, though numerous other feeder designs are on the market available to horse owners. More in-depth comparisons of the different feeder styles available would further help the horse owner maximize the feed intake of the horse and minimize the wastage, thereby decreasing the feed costs of the horse for the owner. The data from this study found that the type of feeder does have an effect on the growth rates and apparent feed efficiency based on feed offered to weanling horses, but no difference was found between treatments in apparent digestibility. Therefore, the authors' hypotheses predicting greater ADG and $\mathrm{G} / \mathrm{F}$ for horses using the combination feeder were accepted, and their final hypothesis related to improved digestibility of dry matter and protein in horses using the combined feeder was rejected. These findings and the implications for using more efficient feeders in other classes of horses in addition to weanling horses warrants further studies to investigate the full extent of the effects of feeder types in various horse feeding systems.

\section{Conclusions}

Changing the type of feeders used to provide hay and grain to young horses can influence the growth performance. Using the simple feeding management procedure of offering hay and grain in a combination of hay and grain feeder with enclosed sides and a manger instead of open-sided hay racks and open-topped feed tubs can improve the growth rates of young horses, most likely due to reduced feed wastage when fed at a rate below ad libitum feed consumption.

\section{References}

[1] Andrew, J. E., Kline, K. H., and Smith, J. L. 2006. "Effects of Feed Form on Growth and Blood Glucose in Weanling Horses.” J. Equine Vet. Sci. 26 (8): 349-55.

[2] Flores, R. S., Byron, C. R., and Kline, K. H. 2011. "Effect of Feed Processing Method on Average Daily Gain and Gastric Ulcer Development in Weanling Horses.” J. Equine Vet. Sci. 31 (3): 124-8.

[3] Bonoma, T. A., Brogren, A. C., Kline, K. H., and Doyle, K. M. 2008. "Effects of Feeding Distiller's Dried Grains with Solubles on Growth and Feed Efficiency of Weanling Horses.” J. Equine Vet. Sci. 28 (12): 725-7.

[4] Martinson, K., Wilson, J., Cleary, K., Lazarus, W., Thomas, W., and Hathaway, M. 2012. "Round Bale Feeder Design Affects Hay Waste and Economics during Horse Feeding." J. Equine Vet. Sci. 90 (3): 1047-55.

[5] Buskirk, D. D., Zanella, A. J., Harrigan, T. M., Van Lente, J. L., Gnagey, L. M., and Kaercher, M. J. 2003. "Large Round Bale Feeder Design Affects Hay Utilization and Beef Cow Behavior.” Journal of Animal Science 81 (1): 109-15.

[6] Belyea, R. L., Martz, F. A., and Bell, S. 1985. "Storage and Feeding Losses of Large Round Bales.” J. Dairy Sci. 68 (12): 3371-5.

[7] Collins, M., Paulson, W. H., Finner, M. F., Jorgensen, N. A., and Keuler, C. R. 1987. "Moisture and Storage Effects on Dry Matter and Quality Losses of Alfalfa in Round Bales.” Trans. ASA 30 (4): 913-7.

[8] Harrigan, T. M., and Rotz, C. A. 1994. "Net, Plastic and Twine Wrapped Large Round Bale Storage Loss.” Appl. Eng. Agric. 10 (2): 188-94.

[9] Martinson, K. W., Coblentz, W., and Sheaffer, C. 2011. “The Effect of Harvest Moisture and Bale Wrapping on Forage Quality, Temperature and Mold in Orchardgrass Hay.” J. Equine Vet. Sci. 31 (12): 711-6. 